\title{
Cold Snaps - children's health in a cold, damp home: influencing policy and practice
}

\author{
Vanessa Powell-Hoyland1*, Catherine Homer2, Anna Cronin de \\ Chavez ${ }^{2}$, Angela Mary Tod ${ }^{3}$, Pete Nelson², Amanda J Stocks ${ }^{4}$ \\ 1 Doncaster Council \\ 2 Sheffield Hallam University \\ 3 University of Sheffield \\ 4 NHS England
}

\begin{abstract}
Children living in cold homes experience worse outcomes. This paper considers some of the findings from the Warm Well Families (WWF) study, which aimed to explore factors influencing the abilities of households including children with asthma to keep warm at home in winter. Individual and group interviews with children, families and professionals were conducted and home temperature and humidity measurements were taken. The experience, knowledge, beliefs and attitudes of adults living in households with children with asthma affect the choices they make. The concept of a 'trade-off' is used, to describe the complex process by which families in fuel poverty are juggling competing priorities in order to make decisions. The paper explores three participant families in detail, through the use of case studies, to illustrate the trade-offs made and the impact of those trade-offs on a family's ability to keep warm and well at home. It is argued that policy initiatives and interventions need to engage with the full range of decisions families make, and the constraints on these decisions, in order to reduce the impact of fuel poverty on the wellbeing of families.
\end{abstract}

Key words: fuel poverty, families, policy, children, health.

\section{Introduction}

The negative impacts on physical and mental health caused by living in a cold home are increasingly well recognised (Harrington et al., 2005; Liddell \& Morris, 2010; Marmot, 2011; Department of Health, 2011a; National Children's Bureau, 2012; Howard, 2015). The combination of increased energy prices, poor quality housing and low and reducing incomes increase the vulnerability of people to cold homes. 
This paper considers some of the findings from the Warm Well Families (WWF) study (Tod et al., 2015), which aimed to explore factors influencing the abilities of households including children with asthma, to keep warm at home. The WWF study followed on from the Keeping Warm in Later Life Project (KWILLT) (Tod et al., 2012) which explored the reasons why older people may struggle to keep warm at home.

The WWF study was conducted in Rotherham and Doncaster, South Yorkshire, England. Both areas have high rates of child poverty. The research team included academics, public health practitioners and a social marketing expert. The purpose of the study was to examine the experience, knowledge, beliefs and values of families and professionals working with families regarding keeping warm at home. These insights will aid understanding of both the constraints and facilitators affecting the ability of families to keep warm and the implications for policy.

The paper explores the methods used to conduct the research which included interviews, focus groups and indoor temperature measurements. The findings are then presented, focusing on the experiences, knowledge and beliefs of families with children with asthma and how these affect the choices and decisions made regarding keeping warm at home. A trade-off model was developed to explain the complex and nuanced process by which families trade off one factor against another in their complex and structurally prescriptive lives (Cronin de Chavez et al., 2014; Nelson et al., 2014; Tod et al., 2015). The detailed working of these trade-offs and the complex bringing together of psychological and structural factors is illustrated through three case studies of participants in the research. Final comments draw on the use of this trade-off model to support policy makers and practitioners to engage with families.

\section{Background: tackling fuel poverty in the UK}

There is a range of evidence supporting the link between cold homes and poorer health within children and young people. Specifically, children living in cold homes are at increased risk of asthma, respiratory infections, slower cognitive development, and higher risk of disability, mental health problems (Liddell, 2008; Liddell \& Morris, 2010), as well as low self-esteem, confidence and educational attainment, poor nutrition, injuries and reduced infant weight gain (Harrington et al., 2005; Marmot 2011; National Children's Bureau, 2012; Public Health England, 2014). Studies on the impact of poor quality housing undertaken by Barnes et al. (2008) and Harker and Shelter (2006) reported that 28 per cent of young people are likely to be at risk of multiple mental health symptoms due to living in a cold home, compared to four per cent of children living in adequate warmth. The costs attributed to the NHS from living in a cold damp home are estimated to be at least $£ 2.5$ billion per annum (Local Government Association, 2014). These issues highlight a real need to tackle fuel poverty. Local authorities and public health teams are well-placed to address these issues through coordinating strategies to improve the energy efficiency of housing stock, increasing levels of employment and income and improving the wellbeing of vulnerable residents.

Identifying who is fuel-poor is more complex than considering income alone. Until 2013, a household was classed as being fuel-poor if they spent more than 10 per cent of their income on energy costs (Department for Environment, Food and Rural Affairs, 2001; Boardman, 2010). In 2013, the government undertook a review, which found this definition of fuel poverty was too broad and failed to identify the most vulnerable. The new definition stated that: 'an individual or family are in fuel poverty if they have low income (below the average median) and high fuel costs (above the average median).' This is known as the Low Income High Costs (LIHC) measure of fuel poverty. Changing the definition has led to a dramatic decrease in the reported numbers of 
households defined as living in fuel poverty; 5.5 million using the 10 per cent definition compared to 3.2 million using the new definition. Of these households, two-fifths included children and one-fifth a child under five (Save the Children, 2011; Hill, 2012). Recent fuel poverty figures using the LIHC measure indicate that of the data collection sites, nine per cent of Rotherham's and 9.8 per cent of Doncaster's population are currently in fuel poverty (Public Health England, 2015a and b).

In the UK, fuel poverty currently affects the most vulnerable people in society, such as families on low incomes living in cold, damp homes. Outcomes of fuel poverty include: cold, damp homes, high healthcare costs, cold-related illnesses, excess winter deaths, and housing in poor repair (HM Government, 2015). The causes of fuel poverty include: low household income and debt, inefficient heating systems, poor quality housing, lack of access to affordable energy and payment options, and ill health/disability resulting in an increased need for a warm home.

Fuel poverty has long been a focus of government policy. The UK government flagship intervention 'Warm Front' was delivered and managed by the Department of Energy and Climate Change (DECC) from 2000 until 2013. Warm Front aimed to reduce energy bills through improving the energy efficiency of properties by offering a range of energy measures targeted at low income groups. The National Audit Office evaluation (2009) highlighted that the programme was cost effective with significant health benefits. However, the intervention failed to reach the most hard to insulate properties, therefore excluding vulnerable 'at risk' groups who are most likely to live in this type of property (DECC, 2014). Over 75 per cent of the households eligible for the scheme and who were in receipt of energy measures were not classed as living in fuel poverty and were not within the 'at risk' groups which included private sector households on low income, older people, young children, long-term sick, and disabled.

The 2011 Energy Act for England, Scotland and Wales included Green Deal and the Energy Company Obligation as replacement interventions for Warm Front (Guertler, 2012). However, the uptake of Green Deal by low income groups and those in private rented sector properties, who arguably would benefit the most, was low and the scheme has now been discontinued (DECC, 2015). As yet there is no replacement national scheme to fund energy efficiency interventions in England, with the exception of the Central Heating Fund which focuses only on off-grid households (HM Government, 2015).

The Fuel Poverty Strategy for England aims to eradicate all fuel-poor homes by 2030, through the implementation of new energy efficiency schemes (HM Government, 2015). However, no additional funding has been identified to develop and deliver such schemes. Howard (2015) argues that the UK spend to eradicate fuel poverty is inadequate and that the current disconnect between the Government's intended fuel poverty interventions, current policy and funding streams, highlights a fuel poverty intervention funding gap of $£ 700$ million per year.

Various UK policies and guidance highlight the links between cold homes and health. In 2011 Public Health England launched the first national cold weather policy (Cold Weather Plan for England, Department of Health, 2011a). The Plan offers professionals guidance on how to identify and make appropriate referrals for individuals and families at risk of health conditions due to living in a cold home. More recently, the National Institute for Clinical Excellence (NICE) produced guidance offering 12 recommendations for voluntary, community and statutory sectors (NICE, 2015). The recommendations include: the development of a strategy; Making Every Contact Count (MECC) in practice; and how to implement interventions to prevent cold-related deaths and morbidity. MECC aims to influence organisations responsible for the care, wellbeing and safety of the public to use every opportunity to achieve health and 
wellbeing. Again, no funding has been set aside for these evidence-based interventions, which perhaps reinforces the view that whilst both the rhetoric around fuel poverty and the evidence of the impact of fuel poverty remain strong, the resources available to support proposed interventions to ameliorate the impact of fuel poverty remain weak.

In order for the policies and guidance to achieve their aims we need to better understand what drives the behaviour of householders. The evidence base regarding older people is relatively advanced, however little is known about the differences in experiences, knowledge and beliefs that may influence the behaviours of families. The WWF study aimed to contribute to meeting that evidence gap.

\section{Methodology}

A summary of the methodology and methods is provided here. Further detail can be found in the research reports (Cronin de Chavez et al., 2014; Nelson et al., 2014) and a sister paper (Tod et al., 2015). The data collection was undertaken in Doncaster and Rotherham, during the winter of 2012/13. Both areas have high levels of fuel poverty, poor housing stock and higher than average incidence of respiratory conditions (Public Health England, 2015a; Barnes, 2008; Masoli et al., 2004). An advisory group supported the design and development of the study. The advisory group included a range of Local Authority and voluntary sector professionals working with families in 'frontline' and strategic roles.

The study was conducted in two stages. Stage one included semi-structured interviews with parents and staff throughout the winter of 2012/13. Stage two was conducted in March - June 2013 and comprised of focus groups conducted with children, young people and professionals working with families. Purposive sampling (Patton, 2012) was used at both stages to include a range of key characteristics including: size of the family, location, age of children, housing type and tenure, income, health and severity of asthma, and ethnicity.

\section{Sample and recruitment}

Thirty five semi-structured interviews with parents of children who have asthma were conducted to capture the views and experiences of those living in cold damp homes. Recruitment of families was supported using hospital admission data to identify areas with a high incidence of respiratory problems in young children and families. Parents were recruited through Local Authority parent support workers; children centre staff; local community groups and children's voluntary organisations. The families varied in terms of lone and two parent households, income and employment status, household tenure, numbers and ages of children (see Table 1). 
p. 61. Cold Snaps - children's health in a cold, damp home: influencing policy and practice

Table 1: Participant Characteristics

\begin{tabular}{|c|c|c|c|c|c|c|c|c|c|c|}
\hline Participant & $\begin{array}{l}\text { Ethnicity of person } \\
\text { interviewed }\end{array}$ & Age & $\begin{array}{l}\text { Employment } \\
\text { of person } \\
\text { interviewed }\end{array}$ & $\begin{array}{l}\text { Employment } \\
\text { partner }\end{array}$ & Children & $\begin{array}{l}\text { Income } \\
\text { weekly - less } \\
\text { than }\end{array}$ & Tenure & Type & Insulation & $\begin{array}{l}\text { Reported } \\
\text { damp }\end{array}$ \\
\hline 1 & White British & 46 & No & No & 1 & $£ 577$ & Privately rented & Semi & Cavity \& loft & No \\
\hline 2 & White British & 30 & Yes & No & 4 & $£ 379$ & Privately owned & Terrace & Cavity \& loft & Yes \\
\hline 3 & White British & 37 & No & No & 3 & $£ 259$ & Rented council & Terrace & Cavity and loft & Yes \\
\hline 4 & White British & 29 & Yes & Yes & 2 & $£ 577$ & $\begin{array}{l}\text { Rented } \\
\text { council }\end{array}$ & Semi & Loft & Yes \\
\hline 5 & White British & 29 & No & No & 1 & $£ 259$ & $\begin{array}{l}\text { Rented } \\
\text { Private }\end{array}$ & Terrace & Loft & No \\
\hline 6 & White British & 21 & No & Single parent & 1 & $£ 259$ & $\begin{array}{l}\text { Rented } \\
\text { Private }\end{array}$ & Terrace & Cavity and loft & No \\
\hline 7 & Pakistani & 42 & No & Single parent & 5 & $£ 259$ & Privately rented & Terrace & Don't know & Yes \\
\hline 8 & Black British & 42 & Yes & Yes & 2 & $£ 259$ & Rented council & Flat & None & Yes \\
\hline 9 & $\begin{array}{l}\text { Dual heritage (what } \\
\text { are the two } \\
\text { ethnicities? }\end{array}$ & 32 & No & Yes & 4 & $£ 379$ & Privately owned & Terrace & No & No \\
\hline 10 & Egyptian B & $?$ & No & No & 4 & Doesn't know & Privately owned & Terrace & Loft & Yes \\
\hline 11 & Black B & 41 & No & No & 3 & $£ 259$ & Privately owned & Terrace & Loft & Yes \\
\hline 12 & White B & 36 & No & Single parent & 2 & $£ 259$ & Privately owned & Terrace & Loft & Yes \\
\hline 13 & White B & 33 & No & Single parent & 2 & $£ 259$ & Rented council & Semi & Loft & \\
\hline 14 & White B & 46 & Yes & Yes & 2 & $£ 577$ & $\begin{array}{l}\text { Rented } \\
\text { Private }\end{array}$ & Semi & Loft & Yes \\
\hline 15 & White B & 34 & Yes & Yes & 3 & $£ 259$ & Privately owned & Terrace & Cavity and loft & No \\
\hline 16 & White B & 31 & No & Yes & 2 & $£ 379$ & Privately owned & Semi & Loft & Yes \\
\hline 17 & White B & 23 & No & Yes & 3 & $£ 259$ & Privately rented & Semi & Loft & No \\
\hline 18 & White B & 28 & No & No & 2 & $£ 259$ & Rented council & Semi & Loft & Yes \\
\hline $\begin{array}{l}19 \\
\text { (Rotherham } \\
\text { participant } \\
\text { number 1) }\end{array}$ & White B & 28 & No & Single parent & 2 & $£ 535$ & Rented council & Flat & $\begin{array}{l}\text { Doesn't know } \\
+ \text { no loft } \\
\text { insulation }\end{array}$ & Yes \\
\hline
\end{tabular}

(c) 2016 The Author

Journal Compilation @ 2016 PPP

People, Place and Policy (2016): 10/1, pp. 57-76 
p. 62. Cold Snaps - children's health in a cold, damp home: influencing policy and practice

\begin{tabular}{|c|c|c|c|c|c|c|c|c|c|c|}
\hline $20(2)$ & White B & 42 & No & Single parent & 7 & $£ 774$ & Living with relatives & Semi & Cavity \& loft & No \\
\hline $21(4)$ & White B & 27 & Yes & Yes & 2 & $£ 487$ & Rented council & Semi & Cavity and loft & Yes \\
\hline $22(5)$ & White B & 33 & Yes & Yes & 2 & Didn't know & Privately rented & Semi & None & No \\
\hline $23(6)$ & White B & 29 & Yes & Yes & 3 & $£ 769$ & Privately owned & $\begin{array}{l}\text { Mid- } \\
\text { townho } \\
\text { use }\end{array}$ & Cavity and loft & No \\
\hline $24(7)$ & White B & 30 & Yes & Yes & 4 & $£ 600$ & Privately rented & Semi & None & Yes \\
\hline $25(8)$ & White B & 44 & Yes & Single parent & 3 & $£ 280$ & Rented council & Terrace & $\begin{array}{l}\text { C + doesn't } \\
\text { know }\end{array}$ & Yes \\
\hline $26(9)$ & South Asian & 38 & Yes & Yes & 3 & $£ 325$ & Privately owned & $\begin{array}{l}\text { Detach } \\
\text { ed } \\
\text { Victoria } \\
\text { n }\end{array}$ & Cavity and loft & No \\
\hline $27(10)$ & Saudi Arabian & 27 & Yes & Yes & 2 & $£ 577$ & Privately owned & Semi & Cavity and loft & No \\
\hline $28(11)$ & White B & 40 & Yes & Yes & 1 & $£ 325$ & Rented council & $\begin{array}{l}\text { End } \\
\text { terrace }\end{array}$ & Cavity and loft & Yes \\
\hline $29(12)$ & White B & 27 & Yes & Yes & 1 & $£ 625$ & Privately owned & Semi & Cavity and loft & No \\
\hline $30(13)$ & White B & 33 & Yes & Yes & 1 & $£ 575$ & Privately owned & Semi & Cavity and loft & Yes \\
\hline $31(14)$ & White B & 18 & No & Single parent & 1 & \begin{tabular}{|l}
$£ 220+$ \\
housing and \\
council tax \\
benefit
\end{tabular} & Privately rented & Semi & $\begin{array}{l}\text { Doesn't know } \\
+\mathrm{L}\end{array}$ & Yes \\
\hline $32(15)$ & White B & 44 & No & Single parent & 2 & $£ 200$ & $\begin{array}{l}\text { Rented housing ass- } \\
\text { ociation }\end{array}$ & Semi & $\begin{array}{l}\text { Doesn't know } \\
+\mathrm{L}\end{array}$ & No \\
\hline $33(16)$ & White B & 38 & Yes & Yes & 2 & $£ 1604$ & Privately owned & Semi & $C+$ part $L$ & Yes \\
\hline $34(17)$ & White B & 32 & Yes & Yes & 2 & $£ 600$ & Privately owned & $\begin{array}{l}\text { End } \\
\text { terrace }\end{array}$ & $C+L$ & No \\
\hline $35(18)$ & White \& B & 27 & No & Yes & 3 & $\begin{array}{l}£ 200+\text { council } \\
\text { tax benefit }\end{array}$ & Privately rented & $\begin{array}{l}\text { Mid- } \\
\text { terrace }\end{array}$ & Doesn't know & Yes \\
\hline
\end{tabular}


Tiny Tag Ultra 2 devices were placed in the participant's living room and the asthmatic child's bedroom two weeks before the interviews took place. The devices recorded the hourly temperature and humidity of each room. Recommended adequate indoor temperatures are $18-21^{\circ} \mathrm{C}$ (Department of Health, 2011). The measurements were used alongside the interview data to determine how actual temperatures compared to how cold householders felt. The findings section includes examples of the Tiny Tag data.

Staff groups from health, social care and education were recruited from Local Authority, National Health Service (NHS) and community and voluntary sector organisations. A process map of strategic and front line staff that work for or with families was developed to identify appropriate staff to approach for interview. Staff were interviewed to explore their perceptions of priorities within the home, i.e. food or fuel, whether families made the connection between fuel poverty and their child's health and how families managed the resources available to them. The staff findings are not the focus of this paper, analysis of staff data can be found in Cronin de Chavez et al. (2014), Nelson et al. (2014) and Tod et al. (2015).

\section{Data collection}

The interviewer team consisted of two researchers, one male and one female, and one female public health practitioner. A strong emphasis was placed on the project being totally independent from any of the participants' energy or housing providers with the aim of encouraging participants to express their experiences, beliefs and concerns without a fear of it impacting on their housing, bills or repairs. All interviewers were also experienced in interviewing vulnerable families and used their experience to encourage the participants to feel safe and not judged during the interview.

Participants were given participant information sheets, verbal discussion and informed consent was obtained prior to the interviews and focus groups. All of the interviews were digitally recorded and transcribed. Interviews lasted between 20 and 120 minutes and were guided by an interview schedule. In a number of the interviews the whole family was present, however only the parents were interviewed.

To provide a deeper understanding of the issues that families faced and to explore the findings from the individual interviews, eight focus groups were undertaken with additional participants. Four of the focus groups involved staff $(n=25)$ representing a range of organisations including public, voluntary and community sectors. One focus group was also held with families $(n=20)$, two groups with children $(n=15)$ and one group with young people $(n=7)$. The intention behind the focus groups, particularly those with children and families, was not to generate new data as such but rather to validate, or not, the emerging findings from the qualitative interviews and to bring a greater understanding of the issues families faced.

\section{Data analysis}

Data were analysed using a Framework Analysis approach (Ritchie and Lewis, 2003). Framework Analysis involves a systematic process of sifting, charting and sorting the material into key issues and themes allowing the integration of pre-existing themes into the emerging data analysis. The research team took on different roles at each stage of the analysis from independently analysing transcripts, verification, and developing the thematic framework. Through negotiation with the research team the final thematic framework outlined some of the complexities that families experience in relation to keeping their homes warm. These complexities include the contextual (e.g. home type and tenure), social (e.g. networks, access to support), psychological (e.g. 
attitudes, knowledge and beliefs) and attitudinal factors influencing parents' heating decisions.

\section{Findings from the study}

The findings from the study are fully presented in Cronin de Chavez et al. (2014), Nelson et al. (2014) and Tod et al. (2015) but are summarised here prior to a detailed exploration, using the case studies of three participants, to show how the themes manifested in individual lives.

The data revealed a range of themes including: contextual factors, support, attitudes and beliefs, knowledge and awareness. The themes explain the complex world within which families operate and the barriers they encounter in relation to keeping warm. The findings suggest there is interplay between the themes and how they influenced the behaviours of parents regarding keeping their homes warm.

The contextual factors included home type and tenure, household type, method of heating, prevalence of damp and low income. In many cases these factors were outside of a family's control. Many families did not own their own home $(n=15)$ and were therefore reliant on their landlords to make changes to central heating and the energy efficiency of their home. Damp and condensation were an issue in the homes of many of the participants. Householders gave examples of how they managed the problems caused by damp and condensation, but often other contextual factors such as house type and low incomes conspired against them.

Participants accessed support from friends and family, social care and health services. For some participants family and friends were often relied upon for financial support to lend and borrow money for fuel bills and other financial commitments. Others, however, were reluctant to seek support from friends who were in the same financial situation as themselves. Professional help was rarely sought.

Attitudes and beliefs linked to home heating included a fear of debt, beliefs about how a cold home impacts on health, experience of asthma and other priorities such as money for food and lifestyle. There was evidence of fear of debt from large fuel bills which meant that many participants preferred to pay for their fuel via a prepayment meter, even though they knew it was more expensive. This was an active choice, driven by the need for financial control as a means of managing their fear and gave control to families as to when and how much of their budget could be spent on fuel. They reported that this fear of debt influenced how they prioritised their overall spending in order to be in control of their budget. Participants discussed their attitudes and beliefs linked to home heating. The beliefs related to cold, health and asthma varied in terms of how cold homes affected asthma, with both cold and heat being identified as asthma triggers.

Knowledge and awareness of heating systems, impact of cold homes on asthma and health, energy efficiency schemes and sources of trusted information were raised in the interviews. Parents discussed what they knew about how a cold home impacts on the health of their family, particularly in relation to their child's asthma and their knowledge of the services available to help them. They also described how they managed heating systems, what alternative heating strategies they employed and how they managed finances to pay for energy.

The lived reality of the themes is presented using three case studies from the interviews. A case study approach has been taken in order to allow for a richer understanding of individual experiences and the multi-textured story each participant 
told (Yin, 2014). The participants chosen allow specific themes to be fore fronted in each case, but they are by no means unique within the sample and other participants could equally have been chosen as subjects. However focusing on three different families from diverse backgrounds in terms of tenure, age and family support highlights the wide range of experiences captured in the research. The case studies demonstrate how the complex interaction between the themes drives behaviour towards maintaining a warm home.

Pseudonyms have been used to protect the anonymity of the participants. Figures displaying the Tiny Tag Ultra 2 measurements are also presented for each case study. These figures highlight the range of temperature and levels of humidity in the living room and child's bedroom in each home over a two week period prior to the research interview.

\section{Case study 1}

Sarah (30) lived with her partner Dave, both British, and their four children; Ryan (3), Michael (8), Sophie (9) and Betty (10) in a three bedroomed, end terrace property. The house had large gaps around the windows, which were in place before they purchased the property from the council. Sarah was undertaking training and waiting to start a fulltime job as a carer. Dave was unemployed and had no formal qualifications. The family's weekly income was $£ 379$.

Sophie had asthma and hay fever. Sarah thought that the damp in the home affected the children's health: 'Because it creates bacteria and stuff like that; I know they live in damp areas don't they?'

Sarah tried to keep the house as warm as possible for the children, but they often wore extra layers: 'Bringing down a blanket sometimes, as well we like to bring down a big duvet sometimes don't we?' Sarah was not aware of the recommended temperature for a living room or child's bedroom: 'About $15^{\circ} \mathrm{C}$ to $17^{\circ} \mathrm{C}$, I think that's warm enough'. There was a lot of damp in the property.

The house was heated by gas central heating. Sarah had changed suppliers for the first time six months before to get a better deal and save money by getting both gas and electricity from the same supplier. The family paid for the energy by prepayment meters; however, the cost of the heating was a real struggle: 'Cost of it, yeah, I do find it quite a struggle. If have the heating on too much it tends to gobble it, gobble it up, and spending a couple of pounds a day if I keep it on our time so I have to turn it off.'

Sarah was aware that prepayment meters are more expensive but considered it to be the best option for them: 'Because they are prepaid they are a little more costly, but they're easier to manage for myself. I don't get a big bill and panic'.

Both Sarah and Dave were meticulous budget managers but expressed how difficult it was to manage their finances: 'We go on the computer every single day, we go through it every day and try and keep track of it all. Never worked out like!' 


\section{Figure 1: Case Study 1 child's bedroom tiny tag}

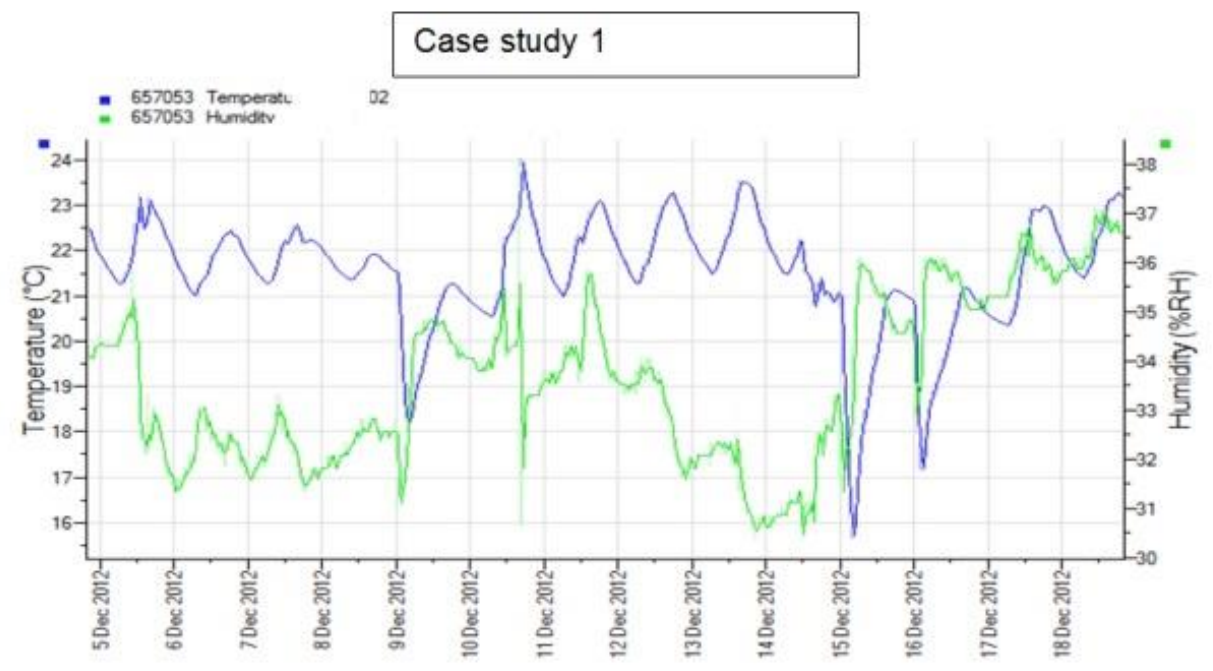

Figure 2: Case Study 1 living room tiny tag

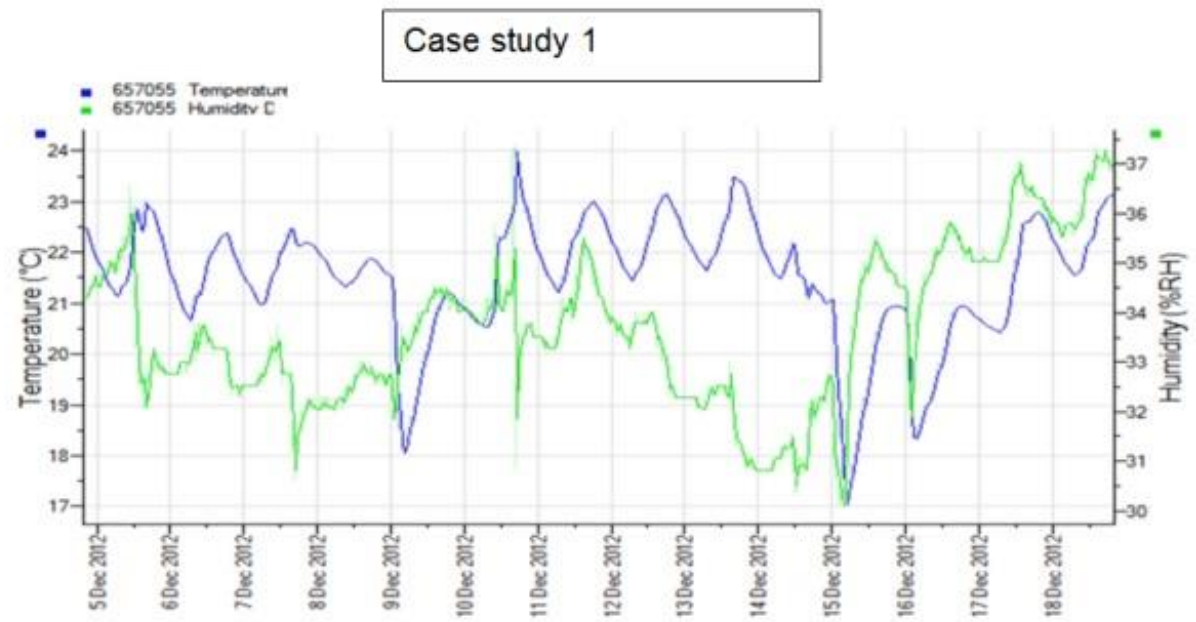

The case study highlights how Sarah prioritised spend on heating the home and keeping the house warm for the children. This was evident in the temperature graphs which showed the rooms are generally within or above the recommended temperature range of $18-21^{\circ} \mathrm{C}$. However Sarah's knowledge of the ideal temperature range, which she felt should be between 15 and $17^{\circ} \mathrm{C}$, is not adequate suggesting that they were using thermal comfort to judge heating needs not actual temperatures. This case study shows that the family pay a lot of attention to managing their finances and cutting their costs. However, the fear of debt and not being able to manage their money if a large heating bill came unexpectedly influenced them to value payment by a pre-payment meter which they were aware was more expensive. This self-disconnection from using their heating system also enabled them to control their spending on the meter. They 
had traded off some financial costs for peace of mind with their payments. Being home owners they were responsible for energy efficiency improvements themselves and there was no free energy efficiency intervention available for this family.

\section{Case study 2}

Cheryl was a 21 year old British single parent, with a two year old daughter, Jenny. They lived in a privately-rented two bedroomed terraced house, which, like many in the area, had been modernised with two previously small rooms being made into one and with a laminate floor which was not carpeted. The house had loft insulation. Cheryl was unemployed and claimed job seekers allowance and income support. She had an income of $£ 259$ or less a week.

Cheryl was not sure about the diagnosis of Jenny's health but she knew her health was poor 'she always picks something up, she's always got a rustley chest, a cough, snotty nose, she's always got something'. Jenny had been to hospital frequently for various problems including bronchitis and had an inhaler and other treatment. Cheryl had not thought that the temperature of the house affected Jenny's health until staff at Sure Start told her about it: 'Like I know her room it is cold, whereas this room were, but my landlord's just put me a new radiator in and there is a difference, so I don't know if it's her radiator's not big enough or I don't know'. She was aware that Jenny's room is quite cold: 'Yeah, that is the coldest room other than like my kitchen and bath room, I think her room's too cold for her. She sleeps with a blanket on in, well she sweats throughout the night anyway but she's still cold even though she's sweating'.

The house had gas central heating and a gas fire which was never used. Cheryl had never switched supplier and paid her bills by pre-payment card and meter. She preferred this method of payment 'Just so like then if I've got money for it I just put it on, I don't like the fact that I've got a bill coming in every so often'. She was in arrears with gas and electric and was paying this back on her meter. The heating system did not have a thermostat and was controlled by a switch on the boiler "I've got to traipse upstairs every time I want it on or hot water".

Cheryl spends a lot of time out of the house getting support from the local nursery and her parents. When they go out then she does not put the heating on in the morning 'there's no point by the time it's warmed up we're going out'. 


\section{Figure 3: Case Study 2 child's bedroom tiny tag}

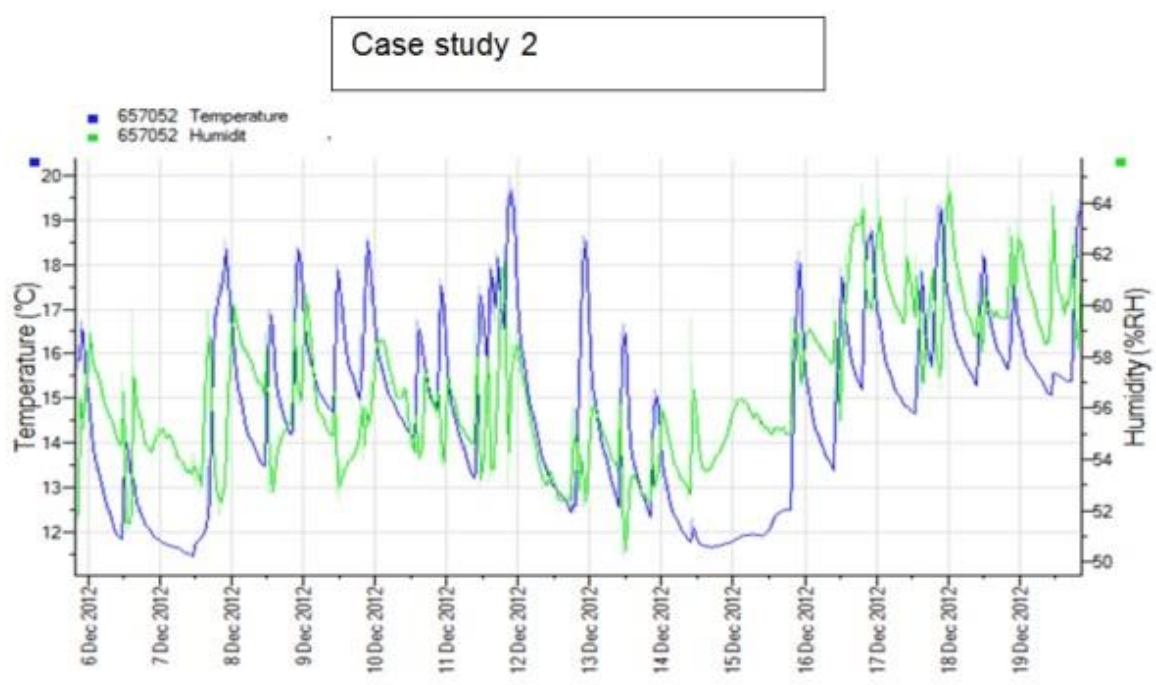

Figure 4: Case Study 2 living room tiny tag

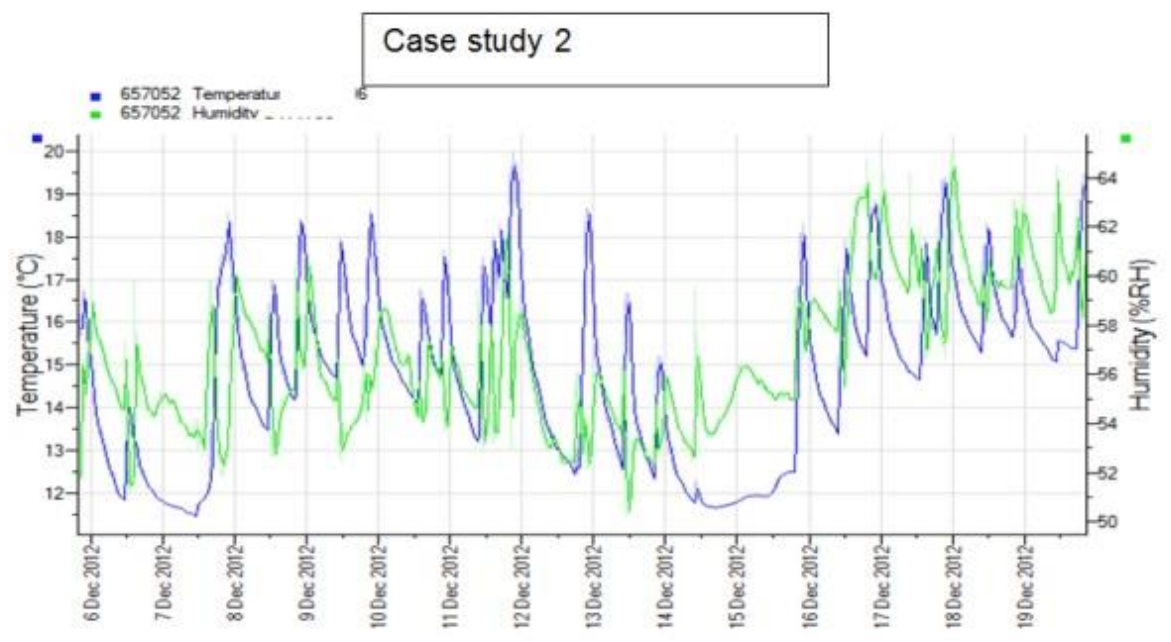

Case study 2 details a family living in private rented accommodation where Cheryl is reliant on her landlord to make changes to the heating system. She is aware that her daughter sleeps in a cold room and that her daughter's respiratory health is affected by the cold. However she is not completely sure what is happening with her daughter's health and although the landlord did install a new radiator, she isn't sure why her daughter's room isn't any warmer. Not having a thermostat is inconvenient for Cheryl as she has to go upstairs to turn the heating on and off. This on/off method of heating the home is demonstrated through the peaks and troughs on the temperature charts and is widely acknowledged as an inefficient way of heating the home. A stable temperature is never maintained and peaks and troughs of humidity accompany the temperature fluctuations. Analysis of the Tiny Tag data indicates that the temperature in the house was above 18 degrees centigrade for only 7.7 per cent of the time during the study period. Cheryl's debt on her meter also indicates the difficulties faced in paying for her 
heating. With the practical and financial challenges of heating her home, Cheryl chooses to trade off the comfort of being in her own home to seeking alternative, warm spaces for her and her daughter such as her parents' house or the nursery. She also chooses to save money by not putting the heating on before they go out. Whilst this means her daughter gets up in a cold home, the short exposure to cold is traded off for financial benefit.

\section{Case study 3}

David was a 42 year old British man who lived with his 30 year old wife Lesley and two children Abigale (6) and Ryan (2). They lived in a modern two bedroomed second floor council flat. The windows were large and the light flooded into the living room. David was employed part-time as a fitness instructor. Lesley was pursuing an English course at college and had a cleaning job. They had an income of $£ 259$ or less per week. Their income fluctuated depending on David's job and was currently lower than it had been for some time 'I get calls and they book me for hours, so then they have not been calling me for a while'.

Their daughter Abigale was asthmatic and used a blue (reliever) and brown (preventer) inhaler. Her parents thought the asthma got worse from mid-November onwards. She was in hospital many times before asthma was diagnosed and had missed school on occasions.

The house was heated by gas central heating and paid for by pre-payment card. David believed that pre-payment card was the only option as a means of payment required by his landlord (however, after investigation from the research team this was identified as David's perception rather than reality). The heating system had a thermostat and was set at $25^{\circ} \mathrm{C}$. The house was described as warm and the family would not like it to be any warmer. The family had problems with mould and damp.

'Dark, really black, and the smell as well...She started having breathing problem while she's sleeping from December. We started, I start doing some research and mould, I thought that mould could be a problem and we had a lot of mould in our bedrooms. A lot of condensation on the windows, yeah we had damp problems'.

David did some research on the internet and found that spraying could kill the spores of the fungus 'I never knew it was a kind of fungus' which alongside ventilation had greatly reduced the damp problem. They had previously always kept the windows closed to keep the heat in. David got no help from family or friends in paying their bills and the family always manage to pay them but 'It's very tight. The budget is very tight now yes...energy bill, it takes a lot of money from your budget'. 


\section{Figure 5: Case Study 3 child's bedroom tiny tag}

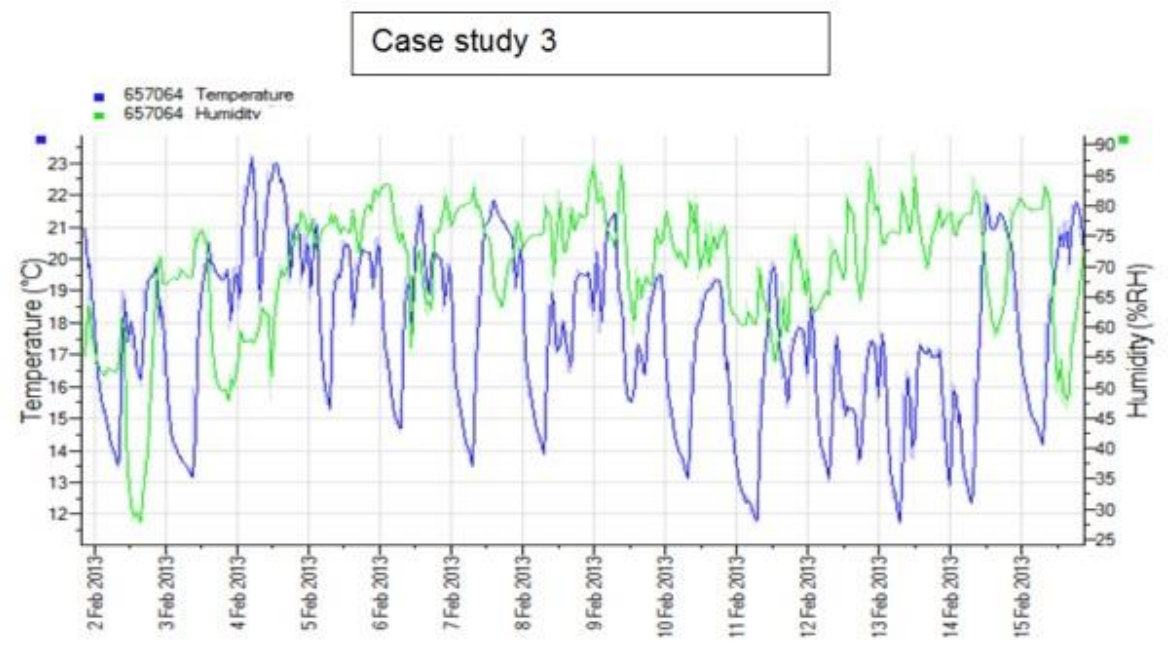

Figure 6: Case Study 3 living room tiny tag

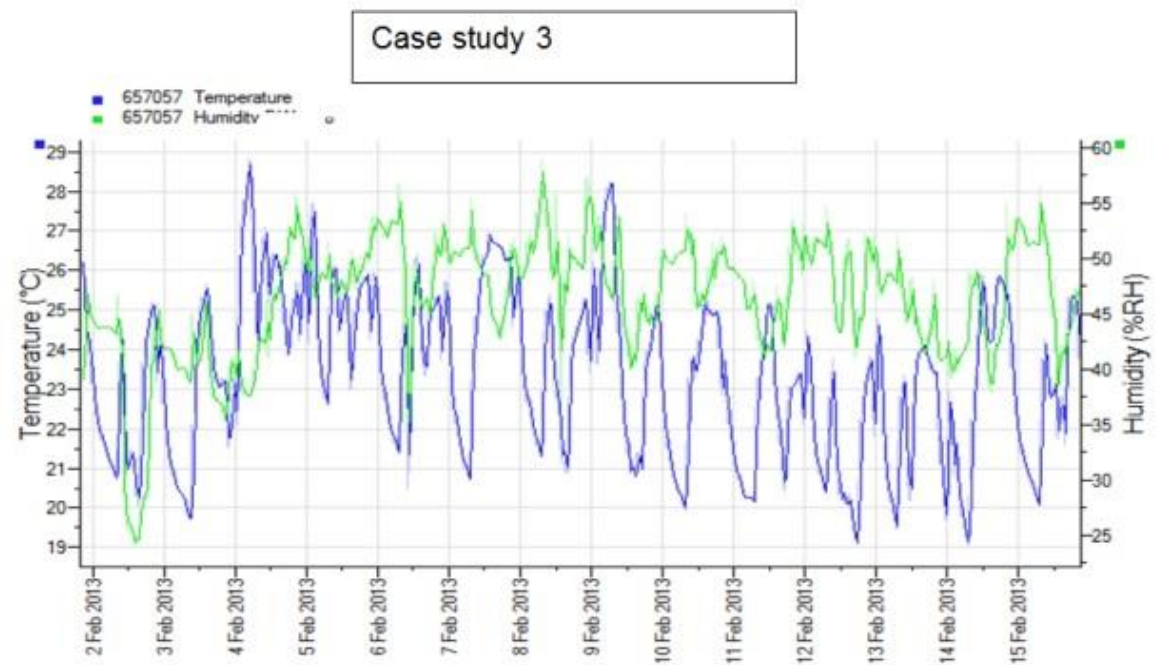

David and Lesley have made an observation that Abigale's asthma is worse in winter but haven't discerned whether this is due to cold indoor or outdoor temperatures, or both. They were very concerned about the mould and condensation in the house but weren't sure how to reduce it. They were motivated to find a solution and open to changing their behaviour. They said the thermostat was set at $25^{\circ} \mathrm{C}$ although the temperature charts do not reflect this temperature was maintained. They believed they had to pay for their gas by pre-payment meter and didn't know they had a choice. The family traded off a loss of heat against opening the window for increased ventilation. However Tiny Tag data indicates high levels of humidity remain despite their best endeavours. 


\section{Discussion}

The findings of the study provide new evidence relating to the factors that influence parent's ability to provide a warm home for their children. The link between cold homes and poor health is widely made in literature and policy guidance (Child Health Impact Working Group, 2007; Liddell and Morris, 2010; Marmot, 2011; Department of Health, 2011). This study adds to this evidence, with findings highlighting how homes with fluctuating temperatures, damp conditions or mould can inadvertently worsen the health of children (see case study 3 ). This paper illuminates the lived reality of fuel poverty for families and highlights the complexity of issues with which policy and resources need to be able to engage.

The research demonstrated how parents assessed their family's needs against the resources available to them. The parents demonstrated skills in managing and allocating restricted budgets and in planning for additional expenditure. Parents also managed their own time and resources, and discussed how they provided help and support, drawing on extended family and friends, highlighting how they often, but not in all cases, turned to peers and family members for financial support and advice, rather than professionals (see Case Study 2).

All the case studies presented in this paper demonstrate the need to 'juggle' or manage priorities against resources which often involved parents making 'trade-offs'. It is proposed, therefore, that these trade-offs drive behaviour and, in conjunction with the parent's ability to take positive actions when faced with difficult circumstances or challenges, are ultimately the governing factors that will determine the level of vulnerability to cold related illness for that child. These trade-offs form a crucial consideration when trying to understand a family's heating behaviour because, in reality, families are faced with making concurrent decisions around heating, food, emotional wellbeing, shelter, education and so on. This level of complexity is not always given full consideration when research looks at one particular aspect of family life, such as heating. The trade-off model (summarised in Figure 7, below) developed from the research represents some of the contextual and psychological factors which impact on family lives and aims to help professionals understand how similar challenges may lead to differing behaviour and outcomes within different families with similar characteristics (Tod et al., 2015). 


\section{Figure 7: The trade-off model}

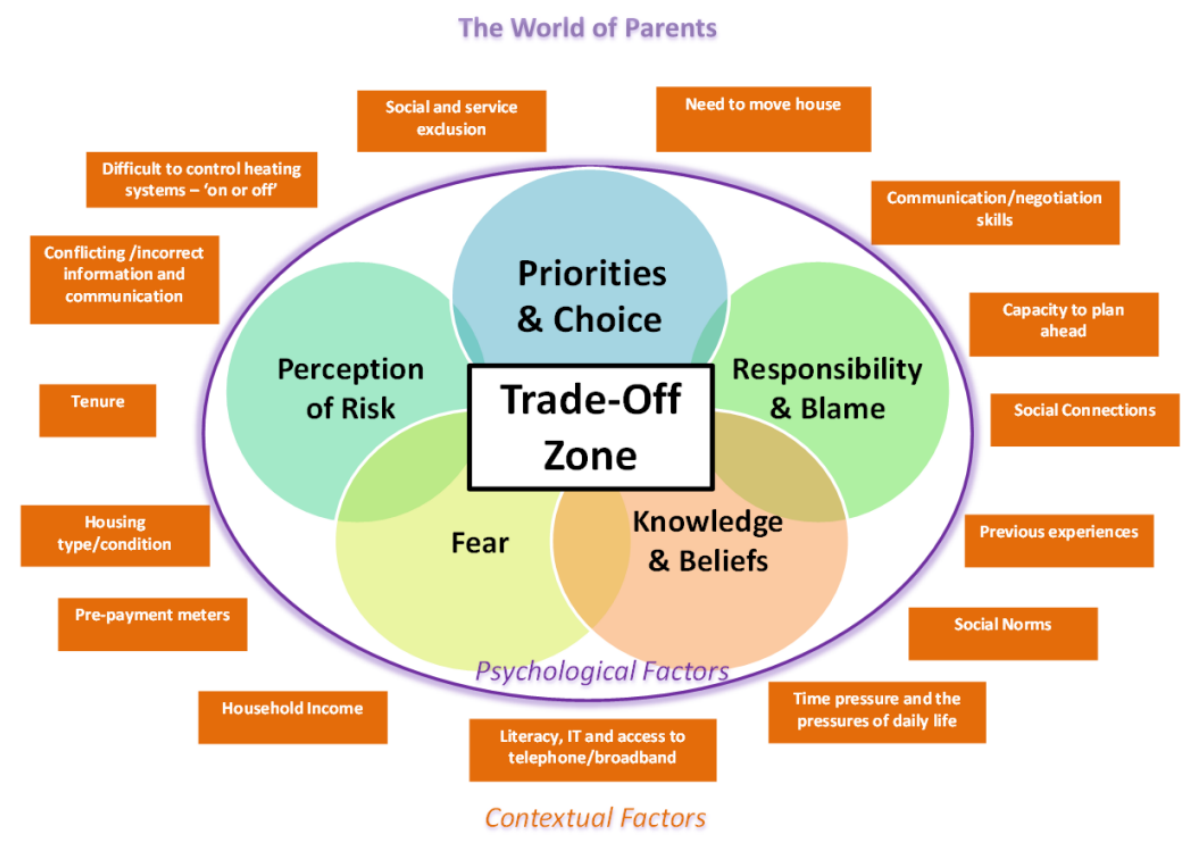

The case studies identify some of the trade-offs that parents make in order to provide a warm home. All three case studies demonstrate how parents were scared of getting into debt with their energy companies. Even though they are aware that paying for energy using a pre-payment meter is more expensive than by direct debit, they preferred the peace of mind that they were managing their money and would not receive a large bill that they may not be able to afford to pay. A pre-payment meter gives control to the household, with formal disconnection rare but self-disconnection whereby the householder will stop adding credit to the prepayment meter or turn the heating off to save money on fuel costs was used as a financial management strategy. These findings support those of Consumer Focus (2010) and Purcell (2014) who identified that, of the 6.5 million prepayment meter customers in the UK, the majority use the meters out of choice despite dissatisfaction with poor customer service and higher tariffs. The findings demonstrated how parents can self-disconnect by turning the heating off and using other strategies to keep warm. Case Study 2 highlights how this self-disconnection leads to temperatures below the recommended range and impacts on the health of the child. Therefore interventions such as Community Energy co-ops, the Big Switch and energy companies which all aim to help people change tariffs are unlikely to support the people who are most likely to self-disconnect. Interventions therefore need to address the knowledge, beliefs and trade-offs that drive the behaviours of people who prefer to pay for their energy by pre-payment meters.

Families on low incomes are, by necessity, experts in budget management. In order to bring about changes in behaviour, positive benefits must be clearly evidenced. Families who trade off more expensive fuel to avoid relatively small amounts of debt are unlikely to take on the larger burden proposed under initiatives such as Green Deal and the Energy Company Obligation (Guerther, 2012; Booth and Choudhray, 2013). We can learn from the WWF findings to develop clear accessible messages regarding financial inclusion and household budgeting and to incorporate those messages into targeted policy development. 
The findings demonstrated how the combination of psychological factors and contextual factors drive behaviour. Trade-offs are not made in isolation, but families make a lot of trade-offs at the same time. A pre-payment meter combined with poor heating equipment with a lack of timer/thermostat and used only by turning on and off will increase the risk of cold impacting on child health. The peaks and troughs of the temperature charts indicate the implications of this pattern of usage, one which impacts not only on temperature, child health, and child development but also budget, as this is an uneconomical way to heat a home (Munton et al, 2014; Consumer Focus, 2012). An intervention which provides a timer could be effective, however an intervention which provides budget management may not be. If trade-offs made in the management of a household and the care of a family are not better understood and acknowledged then policies aiming to help these families are at risk of failing. In the current climate of severely reduced voluntary and public sector funding, particularly in terms of access to energy efficiency interventions and reducing the health impacts of fuel poverty, the trade-off model presents a potential for more effective interventions, and also a format for collaborations between organisations and campaigns for multiple issues facing families experiencing fuel poverty.

Rather than assuming that multiple beliefs, behaviours and attitudes found among families in this study are diverse but fixed, it is perhaps more useful to consider the context in which these are played out. This is important in terms of understanding behaviour, knowledge and beliefs but also critical to understanding policies and interventions. Policies are often developed targeting one health, housing, environmental, educational or social care issue and isolated from the other priorities and struggles families are simultaneously experiencing. Drawn from our data, the trade-off model presents a fuller picture of the priorities, needs and choices, householders are facing alongside the need to keep warm. This is far more complex, and hopefully far more insightful than the simplistic 'heat or eat' scenario posed by organisations aiming to draw attention to the financial challenges faced in the UK (Purcell, 2014). By understanding the trade-offs, what may appear to be 'wrong' or 'unhealthy' financial choices may actually make good sense if child and family wellbeing is viewed holistically rather than through the potentially blinkered sight of an individual profession.

\section{Conclusion}

Families with children with asthma who live in cold homes are at risk of poor health. This paper has presented findings that indicate that professionals and policy makers in public health need to understand the complex world in which families are required to make difficult decisions about a household's health and wellbeing. The experience, knowledge, beliefs and attitudes of adults living in households with children with asthma affect the choices they make. The concept of a 'trade-off' is used to describe the complex process by which families in fuel poverty are managing or juggling competing priorities against resources in order to make decisions. Understanding the decisions made and the trade-offs families make will enable both policy and interventions to be targeted to those most in need.

\section{Acknowledgments}

We would like to thank the funders of the WWF study (Consumer Futures now Citizens Advice Bureau, Doncaster Metropolitan Borough Council Public Health, Rotherham Metropolitan Borough Council Public Health and Collaboration for Leadership in Applied 
Health Research and Care South Yorkshire), the families and staff who participated in the project and members of the advisory group at each study site.

This article presents independent research by the National Institute for Health Research Collaboration for Leadership in Applied Health Research and Care for South Yorkshire (NIHR CLAHRC SY) a pilot which ended in 2013. Further details about the new NIHR CLAHRC Yorkshire and Humber can be found at www.clahrc-yh.nihr.ac.uk. The views and opinions expressed are those of the authors, and not necessarily those of the NHS, the NIHR or the Department of Health.

* Correspondence address: Vanessa Powell-Hoyland, Public Health, Doncaster Council, Doncaster, England. Phone: 01142255815 / Email: vanessa.powellhoyland@doncaster.gov.uk

\section{References}

Barnes, M., Butt, S. and Tomaszewski, W. (2008) The Dynamics of Bad Housing: The Impact of Bad Housing on the Living Standards of Children. London: National Centre for Social Research.

Boardman, B. (2010) Fixing fuel poverty: challenges and solutions. London: Earthscan.

Booth, A.T. and Choudhary, R. (2013) Decision making under uncertainty in the retrofit analysis of the UK housing stock: Implications for the Green Deal. Energy and Buildings, 64, 292-308.

Child Health Impact Working Group (2007) Child Health Impact Assessment of Energy Costs and the Low Income Home Energy Assistance Program. http://www.hiaguide.org/hia/child-health-impact-assessment-energy-costs-andlow-income-home-energy-assistance-program-liheap [Accessed: November 2015]

Consumer Focus (2010) Cutting back, cutting down, cutting off, Self-disconnection among prepayment meter users. London: Consumer Focus.

Consumer Focus (2012) Consumers and domestic heating controls: a literature review. London: Consumer Focus.

Cronin de Chavez, A., Tod, A., Homer, C., Nelson, P., Stocks, A. and Powell-Hoyland, V. (2014) Warm Well Families: Rotherham Final Report. Sheffield: Sheffield Hallam University. Available at: http://shura.shu.ac.uk/7906/1/Rotherham Final_Report_March_2014.pdf [Accessed: November 2014]

Department of Energy and Climate Change (2014) Process Evaluation of the Warm Front Scheme. Available at: https://www.gov.uk/government/uploads/system/ uploads/attachment_data/file/322901/Warm_Front_Evaluation_Report.pdf [Accessed: June 15]

Department of Energy and Climate Change (2015) Green Deal Finance Company funding to end. Available at: https://www.gov.uk/government/news/green-dealfinance-company-funding-to-end [Accessed: November 2015]

Department for Environment, Food and Rural Affairs (2001) The UK Fuel Poverty Strategy. London: Department for the Environment Food and Rural Affairs and Department of Trade and Industry.

Department of Health (2011) Cold Weather Plan for England: protecting health and reducing harm from severe cold. London: Department of Health Available from http://www.dh.gov.uk/health/2011/11/cold-weather-plan/ [Accessed: July 2015]

Guertler, P. (2012) Can the Green Deal be fair too? Exploring new possibilities for alleviating fuel poverty. Energy Policy, 49, 91-97.

Harker, L. and Shelter (2006) Chance of a lifetime: The impact of bad housing on children's lives. London: Shelter. 
Harrington, B.E., Heyman, B., Merleau-Ponty, N., Stockton, H., Ritchie, N. and Heyman, A. (2005) Keeping Warm And Staying Well: Findings From The Qualitative arm of the Warm Homes Project. Health \& Social Care in the Community, 13, 259-267.

Hill, J. (2012.) Getting the measure of fuel poverty: final report fuel poverty review. London.

HM Government (2015) Cutting the Cost of Keeping Warm: A Fuel poverty Strategy for England. London. Available at: https://www.gov.uk/government/uploads/ system/uploads/attachment data/file/408644/cutting the cost of keeping wa rm.pdf [Accessed: November 2015]

Howard. R. (2015) Warmer Homes: improving fuel poverty and energy efficiency policy in the UK. Available at: http://www.policyexchange.org.uk/images/publications Lwarmer\%20homes.pdf [Accessed: November 2015]

Liddell, C. (2008) The impact of fuel poverty on children Belfast: Save the Children. Belfast: Ulster University \& Save the Children. Available at: http://tinyurl.com/STCPolicy-Briefing-FP [Accessed: May 2015].

Liddell, C. and Morris, C. (2010) Fuel poverty and human health: a review of recent evidence. Energy Policy, 38, 2987-2997.

Local Government Association (2014) Provisional Local Government Finance Settlement 2015-16. Available at: http://www.local.gov.uk/documents/10180 $\angle 5533246 /$ LGA+On+the+Day+briefing+Provisional+LG+Finance+Settlement201516.pdf/4ce0905f-d881-4426-8a7b-9755ec6d26bc [Accessed: July 2015]

Masoli, M., Fabian, D., Holt, S. and Beasley, R. (2004) Global Burden of Asthma. For the Global Initiative for Asthma. Available at: http://www.ginasthma.org/pdf/ GINABurdenReport.pdf [Accessed: May 2015]

Marmot Review Team (2011) The health impacts of cold homes and fuel poverty. London: Friends of the Earth.

Munton, A.G., Wright, A.J., Mallaburn, P.S. and Boait, P.J. (2014) How heating controls affect domestic energy demand: A Rapid Evidence Assessment. London: Department of Energy and Climate Change (DECC).

National Audit Office (2009) The Warm Front Scheme. Available at http://www.nao.org.uk/report/the-warm-front-scheme [Accessed: July 2015]

National Children's Bureau (2012) Fuel Poverty and Child Health and Wellbeing. Available at: http://www.ncb.org.uk/media/757610/ebr_fuel_poverty_briefing 20june.pdf [Accessed: July 2015]

National Institute for Clinical Excellence (NICE) (2015) Excess winter deaths and morbidity and the health risks associated with cold homes. Guidance No 6 . London 2015. http://www.nice.org.uk/guidance/ng6 [Accessed: November 2015]

Nelson, P., Tod, A., Cronin de Chavez, A., Powell-Hoyland, V. and Stocks, A. (2014) Warm Well Families: Doncaster Final Report. Sheffield Hallam University. Available at: http://shura.shu.ac.uk/7905/1/Doncaster_Final_Report_March_ 2014.pdf [Accessed: November 2015]

Patton, M.Q. (2002) Qualitative Research and Evaluation Methods, $3^{\text {rd }}$ Edition. Thousand Oaks, CA: Sage.

Public Health England (2014) Local action on health inequalities: Fuel poverty and cold home- related health problem. Available at https://www.gov.uk/government/uploads/system/uploads/attachment data/file /357409/Review7_Fuel_poverty_health_inequalities.pdf. [Accessed: June 2015]

Public Health England (2015a) Public Health Outcomes Framework. Available at: http://www.phoutcomes.info/ [Accessed: November 2015]

Public Health England (2015b) Health Profiles. Available at: http://fingertips.phe.org.uk/healthprofiles\#page/1/gid/3007000/pat/104/par/E45000010/ati/102/are/E08000 016 [Accessed: November 2015] 
Purcell, S. (2014) Let us switch! How prepayment meters trap people in fuel poverty. Manchester: Church Action on Poverty.

Ritchie, J. and Lewis, J. (2003) Qualitative research practice. London: Sage.

Save the Children (2011) Rising Energy Costs: The Impact On Low-Income Families. Available at: https://www.savethechildren.org.uk/sites/default/files/docs/Risingenergy-costs-briefing.pdf [Accessed: November 2015]

Tod, A.M., Lusambili, A., Homer, C., Abbott, J., Cooke, J., Stocks, A. and McDaid, K. (2012) Understanding factors influencing vulnerable older people keeping warm and well in winter: a qualitative study using social marketing techniques. BMJ Open, 2, 2:e000922, DOI: 10.1136/bmjopen-2012-000922.

Tod, A., Nelson, P., Homer, C., Cronin-de-Chavez, A., Powell-Hoyland, V. and Stocks, A. (2015, in press) Understanding influences and decisions of households with children with asthma regarding temperature and humidity in the home in winter: a qualitative study. BMJ Open.

Yin, R. (2014) Case Study: research design and methods; fifth edition. Sage publications International. 